\title{
NELSON RODRIGUES LEITOR DE \\ GILBERTO FREYRE: o projeto teatral rodriguiano em aliança com a Sociologia freyreana
}

\section{Henrique Buarque de Gusmão*}

\begin{abstract}
Resumo: Neste trabalho, proponho uma leitura da obra teatral de Nelson Rodrigues tendo em vista algumas questões que estão em jogo no campo teatral da segunda metade do século XX, o posicionamento do autor diante delas e o projeto teatral que ele explicita em seus textos. Dentro de um campo cultural marcado por intensas lutas sociais e políticas, Nelson Rodrigues produz suas peças tendo em vista uma função purificadora e redentora do teatro. Opondo-se a toda uma corrente de teatro engajado, propõe-se um teatro infestado de personagens intensos (tanto na expressão como na repressão sexual) que teriam a função de purificar o público. Esta aposta em um sentido e valor para o teatro dá-se a partir de algumas alianças, como, por exemplo, com a sociologia de Gilberto Freyre. Leitor e profundo admirador desse sociólogo, Nelson apropria-se, dentro de seu projeto teatral, de diversos elementos da sociologia freyriana como os excessos de violência física, sexual e sensual (marcas da hybris), assim como a análise da entrada de padrões de civilização importados que também se impõem pela marca da violência da repressão. A tensão entre o elemento da desmedida e o da disciplina gera uma série de personagens, situações e tensões que atravessam as obras e que podem ser pensadas como elementos de uma aliança estratégica.
\end{abstract}

Palavras-chave: Nelson Rodrigues, Gilberto Freyre, teatro, hybris, civilização.

\footnotetext{
Historiador, ator, integrante da companhia teatral Studio Stanislavski, mestre em teatro pela Unirio e doutorando em História Social pela UFRJ, onde desenvolve a pesquisa Nelson Rodrigues leitor de Gilberto Freyre, sob orientação da professora Andréa Daher. Bolsista CNPq. E-mail: henrique_gusmao@yahoo.com.br
} 


\section{Introdução}

Geneton Moraes Neto, ao entrevistar Nelson Rodrigues, formulou ao dramaturgo a seguinte questão: "Se o senhor fosse levado a fazer uma hipotética opção entre o teatro e o jornalismo, qual dos dois preferiria?" A resposta de Nelson foi a seguinte: "O teatro! E não é um problema de qualidade intelectual não”. Através dessa resposta, Nelson coloca-se como um homem de teatro apesar de sua forte relação com o jornalismo. Analisando-se sua biografia, pode-se entender melhor essa sua auto-representação como homem de teatro.

Em 1943, a montagem de seu texto Vestido de noiva teve uma enorme repercussão. Muitos estudiosos apontaram essa peça como um marco inicial do teatro brasileiro moderno. Ao longo dos anos seguintes, seus textos (quando não enfrentavam problemas com a censura) eram lidos, montados e assistidos por nomes de grande importância do teatro carioca e nacional. Além disso, Nelson Rodrigues engajava-se em diversos processos relativos a seus textos. Por exemplo, em relação à censura, ele, pessoalmente, desenvolvia diversas estratégias para que as peças não ficassem presas nas mãos dos censores, buscava alianças artísticas e políticas para que elas fossem liberadas. Em relação às montagens, elas eram, muitas vezes, acompanhadas pelo autor e, em uma ocasião, Nelson chegou a participar como ator da montagem de um de seus textos - Perdoame por me traíres.

Essa entrada do dramaturgo no campo teatral, entretanto, não se dá de forma desinteressada, muito menos pacífica. Há uma série de lutas e disputas nas quais o dramaturgo em questão se envolve, e essas lutas, analisadas a partir de uma perspectiva sócio-histórica, vão em busca de um sentido e de um valor da própria forma artística que gera aquele campo - no caso, o teatro. Antes de buscar a aposta de sentido e valor de Nelson Rodrigues para o teatro, é importante apresentar uma determinada disputa que pode nos ajudar a perceber 
algumas questões que estão em jogo neste campo teatral brasileiro dos anos 1950, 60 e 70. Trata-se das diversas polêmicas que estouraram entre Nelson e Oduvaldo Vianna Filho, o Vianinha.

\section{Oposições entre Nelson Rodrigues e Vianinha no campo teatral dos anos 1960}

No periódico Brasil em marcha, no ano de 1961, através da publicação de diversos artigos, foi travada uma luta entre os dois dramaturgos. Em relação às personagens das peças de Nelson, Vianinha propunha que elas "nunca têm um problema racional, de consciência, em que as ações subordinam-se a um projeto, a razões e motivos retirados de uma perspectiva que o homem tem de seus condicionamentos." Atravessada por questões políticas, essa crítica está imbuída de um determinado sentido dado ao teatro, o qual, na perspectiva de Vianinha, deveria apresentar questões racionais, ligadas à consciência. Deveria fortalecer projetos de mudança social. Nelson, para Vianinha, "não quer ordem, quer a paixão pura e limpa, como se ela não precisasse de um fundamento ideológico para se manifestar e exigir." A oposição entre paixão e ideologia, caos e ordem mobilizam este tipo de crítica. Em outro trecho é colocado que as peças de Nelson Rodrigues "exaltam o indivíduo que abdicou de sua máxima aspiração de dominar o real e resolveu passar o resto da vida se desencontrando, fulgurante, urrando e batendo no peito como um animal, feliz por não ter de pensar."

No mesmo periódico Nelson responde a Vianinha, defendendo um outro tipo de sentido e valor para o teatro:

No seu ressentimento, o Vianinha nega, de alto a baixo, o meu teatro. E por que nega? É simples: porque eu não faço propaganda política, porque não engulo a arte sectária. Em suma: o Vianinha queria que o Boca de Ouro parasse a peça e apresentasse um atestado de ideologia. Mas ele quer mais. Não basta o personagem. Exige também do autor o mesmo atestado. A minha vontade é perguntar ao 
Vianinha: 'Ô rapaz! Você é revolucionário ou tira?' (apud Castro, 1992, 320).

Nessa resposta, Nelson nega a proximidade entre a esfera política e a artística, proximidade esta que fazia parte do projeto teatral de Vianinha e de uma série de outros artistas daqueles anos. Criticando a idéia de um teatro popular proposto por Vianinha, Nelson afirma que “segundo sua concepção, o 'teatro popular' há de ter o 'mínimo de teatro' e há de excluir, como inútil trambolho, o ser humano" (apud Castro, p. 1992, 320). Coloca-se, então, nesse debate, a idéia de que a arte engajada deixa de lado algo que seria próprio da natureza humana. Nelson identifica, na obra de Vianinha, “em vez de amor, em vez de ódio, em vez das paixões que lembram a besta humana, o 'revolucionário burro' [que] quer o petróleo e seus derivados, quer manganês, quer minérios, quer batatas, quer abacates" (apud Castro, 1992, p. 320). A perspectiva de um teatro engajado, segundo Nelson Rodrigues, produziria não mais dramaturgos e artistas, mas sim "um centauro de Marx de galinheiro com Brecht também de galinheiro” (apud Castro, 1992, p. 320).

\section{O sentido de purificação e redenção no teatro de Nelson Rodrigues}

A partir da apresentação dessa polêmica, podem-se destacar alguns elementos que circulam no campo teatral e são colocados em questão nas lutas de concorrência. A associação com as questões políticas (e revolucionárias), a busca por uma racionalidade dos personagens que contagiasse o público, a degeneração provocada pelos instintos, a força do amor, da paixão, a relação e filiação com nomes do teatro, da política e da intelectualidade internacionais, todas essas são questões que circulam no campo teatral naquele momento e colocam em confronto, no caso, esses dois nomes. A partir delas pode-se começar a tratar da forma como Nelson articula tais elementos em sua aposta de sentido para o teatro. 
Em meados dos anos 1960, Nelson Rodrigues escreveu uma novela para a televisão. Apesar de manter seu estilo, alguns observadores identificaram um autor menos polêmico em seu texto, um pouco mais econômico em relação à violência e à sexualidade. D. Helder Câmara, num encontro à época com Nelson - relatado por seu biógrafo Ruy Castro -, perguntou-lhe sobre as concessões que fizera. A resposta de Nelson é a seguinte: "Não, dom Helder. Quem faz concessões é o gênero, não eu” (apud Castro, 1992, 341).

Nessa resposta de Nelson, aparece claramente uma idéia que busco desenvolver agora: a especificidade do gênero teatral para o autor. Se a teledramaturgia permite concessões, o teatro não as permitiria. Essa idéia do gênero que não admite concessões é um importante indício para se pensar o sentido que Nelson está percebendo e apostando dentro do campo cultural em questão. É justamente na não concessão, no limite da moral, da aceitação e da razão que ele irá entender o lugar e o sentido do teatro. $\mathrm{O}$ trecho a seguir avança nesta discussão:

Morbidez? Sensacionalismo? Não. E explico: a ficção, para ser purificadora, precisa ser atroz. O personagem é vil, para que não o sejamos. Ele realiza a miséria inconfessa de cada um de nós. A partir do momento em que Ana Karenina, ou Bovary, trai, muitas senhoras da vida real deixarão de fazê-lo. No Crime e castigo, Raskolnikov mata uma velha e, no mesmo instante, o ódio social que fermenta em nós estará diminuído, aplacado. Ele matou por todos. E, no teatro, que é mais plástico, direto, e de um impacto tão mais puro, esse fenômeno de transferência torna-se mais válido. Para salvar a platéia, é preciso encher o palco de assassinos, de adúlteros, de insanos e, em suma, de uma rajada de monstros. São os nossos monstros, dos quais eventualmente nos libertamos, para, depois, recriá-los. (apud Castro, 1992, 273).

Nesse trecho - repleto de elementos significativos para se pensar a forma como Nelson se posiciona dentro do campo teatral -, emerge a idéia da purificação. Justamente por não realizar concessão, 
por ser um gênero que deveria ser atroz, violento, excessivo, é que o teatro teria a possibilidade de desempenhar um papel purificador para os seus espectadores. Nelson Rodrigues coloca em questão a necessidade de "salvar a platéia". Para que isso se efetivasse, seria necessária uma rajada de monstros no palco, de assassinos, de crimes atrozes.

Um dos aspectos presentes nesse trecho, que chama muito a atenção, é o entendimento do teatro como uma forma de contato mais direta, pura e forte com o espectador, dando a ele uma capacidade muito potente de atuação e transformação (no sentido da purificação) sobre os homens. Entre outros pensadores estrangeiros, Antonin Artaud (1999, p. 8) é um dos que mais se aproxima desta concepção: "É preciso acreditar num sentido da vida renovado pelo teatro, onde o homem impavidamente torna-se o senhor daquilo que ainda não é, e o faz nascer." Renascimento, purificação, redenção são categorias que Nelson utiliza (certamente numa apropriação e num diálogo com nomes como Stanislavski, Artaud, Grotowski, e, numa outra perspectiva, Aristóteles - a partir de uma apropriação da categoria hybris, que será debatida mais à frente) para pensar e produzir seu teatro. Não é por acaso que a força dos escândalos provocados por uma obra de arte o encantava. Não é por acaso que ele indica que suas peças deveriam ser montadas em colégios de freiras.

A partir dessa concepção de teatro que Nelson Rodrigues coloca em jogo, tornam-se mais compreensíveis e complexas as tensões que ele enfrenta dentro do campo teatral. Uma vez que a cena de seus espetáculos era dominada pelo excesso de perversão, de violência, de sexualidade, em busca de uma redenção do público, ela se afasta muito da cena de um teatro mais ligado a movimentos de esquerda, que busca uma conscientização revolucionária do público e que também busca aliança com referências importantes do teatro mundial (como é o caso de Brecht). O campo teatral daquele momento, então, opõe algumas figuras que disputam o sentido do 
teatro entre si, sendo atravessado por filiações a figuras de grande relevância no cenário internacional, por questões políticas, por sentidos religiosos, por alianças estratégicas. Dentro do sentido que Nelson Rodrigues aposta no teatro e faz com que suas peças sejam produzidas e recebidas, existem muitas alianças relevantes. Uma das mais fortes (pelo excesso quantitativo e qualitativo de citações nas crônicas rodriguianas) vem da Sociologia: Gilberto Freyre.

\section{Violência e civilização na perspectiva da desmedida em Gilberto Freyre}

Chega-se, assim, à hipótese central deste artigo: pode-se pensar a construção do projeto teatral de Nelson Rodrigues a partir de apropriações de figuras, situações, categorias, problemas e concepções da sociologia de Gilberto Freyre. Ou seja, quando se analisam as situações trágicas construídas por Nelson Rodrigues, tendo em vista seus posicionamentos como dramaturgo e homem de teatro, é possível identificar o uso de diversos elementos presentes e recorrentes nos textos de Gilberto Freyre, especialmente em Casagrande \& senzala e Sobrados e mucambos.

Em Casa-grande \& senzala, Gilberto Freyre analisa o processo de formação da sociedade colonial. Em concordância com diversos outros autores que pensaram este processo de formação (como Oliveira Vianna, Sérgio Buarque de Hollanda e Caio Prado Júnior), Gilberto Freyre identifica uma ausência do Estado português nos primeiros momentos da colonização, ficando sob a responsabilidade de aventureiros e de famílias portuguesas a tarefa de devastar, ocupar e explorar o território tropical. É dessa forma que se cria o ambiente detalhadamente desenhado por Freyre, marcado pela grande autonomia e autoridade do senhor de engenho (autoridade que, em diversas situações, enfrentava e superava o poderio metropolitano) e pelas figuras da casa-grande e da senzala. 
Nesse ambiente, a mistura de etnias e culturas foi o que tornou possível o sucesso da ocupação da colônia portuguesa, tendo em vista as dificuldades apresentadas pela terra e pelo momento histórico. Somente a mobilidade, miscibilidade e aclimatabilidade dos portugueses em contato com índios e africanos pôde garantir o sucesso da ocupação do território.

O elogio da miscigenação gerou, muitas vezes, diversas críticas a Gilberto Freyre, posto ter sido muito associado à idéia de “democracia racial”. Ricardo Benzanquen de Araújo, em seu livro Guerra e paz, Casa-grande \& senzala e a obra de Gilberto Freyre nos anos 30, discute como o otimismo da mistura de culturas não exclui a profunda violência do sistema escravocrata que contagia o ambiente social criado na obra de Gilberto Freyre, afirmando que:

da mesma maneira que encontramos em Casa-grande \& senzala um vigoroso elogio da confraternização entre negros e brancos, também é perfeitamente possível descobrirmos lá numerosas passagens que tornam explícito o gigantesco grau de violência inerente ao sistema escravocrata, violência que chega a alcançar os parentes do senhor, mas que é majoritária e regularmente endereçada aos escravos. (Araújo, 1994, p. 45).

Ricardo Benzaquen de Araújo identifica no ambiente social da casa-grande - criado por Gilberto Freyre - uma tensão entre flexibilização e violência entre culturas, relacionada a uma característica que marcaria esta realidade: a hybris. A casagrande freyreana seria caracterizada por um ambiente de excessos, principalmente sexuais, que aproximam o português da negra e da índia e que gera um "clima extremamente orgiástico na casagrande", um ambiente de "culto à obscenidade" (Araújo, 1994, p. 63 - 68). Se a violência do senhor de engenho, a sua preguiça, o trabalho do escravo, a violência para com o negro (extravasada para a própria família do senhor) seriam excessivas, o ambiente sexualizado das casas-grandes também o seria. Um ambiente sexualizado marcado pela violência, pela perversão também em excesso. Assim, “apesar 
da mestiçagem, da tolerância e da flexibilidade, o inferno parecia conviver muito bem com o paraíso em nossa experiência colonial" (Araújo, 1994, p. 46)

É a partir dessa perspectiva que Freyre se utiliza do conceito de "equilíbrio de antagonismos". ${ }^{1}$ Equilíbrio entre povos e culturas distintas, entre violência e miscigenação. Esse equilíbrio, conquistado e efetivado dentro do complexo casa-grande e senzala garantiu o sucesso da colonização, garantiu a vitória da família sobre todas as dificuldades que impunham o meio e as circunstâncias. Há, então, na análise de Freyre sobre a formação da sociedade colonial, uma espécie de redenção social a partir das diferenças, da violência, da sexualidade, dos excessos que marcaram esse processo a partir da ação dos conquistadores. Daí define-se a predominância do nível privado sobre o público, o papel central da família e as relações pessoalizadas na configuração social que se constituía.

Figuras que poderiam representar um certo grau de repressão e uma tentativa de disciplinarização desses ambientes (como os padres jesuítas), não conseguiriam ter força suficiente naquele momento. Sendo assim, dentro da casa-grande, monta-se um clima altamente sexualizado, onde senhores se relacionam com escravas, meninos com cabras ou com crianças negras e até mesmo o incesto pode ser encontrado, onde a violência ultrapassava as relações entre senhor e escravo, onde a figura do patriarca se impunha com um enorme nível de rigor. E esses dados representavam a vitória da família nos trópicos nos moldes da hybris.

Ainda em Guerra e paz, Ricardo Benzaquen de Araújo analisa a obra de Gilberto Freyre Sobrados e mucambos. Pesquisando, agora, a sociedade imperial brasileira, Freyre percebe que um determinado "projeto civilizador" ganha força no Brasil com a chegada da família real. A mineração já teria acentuado um certo caráter repressor e disciplinarizador na sociedade brasileira, uma vez que a Coroa portuguesa fez-se aqui mais presente. A chegada da Corte, entretanto, 
traz novos hábitos, novos produtos, novas expressões culturais que entrarão em choque com o "clima quase delirante, assinalado pelos mais imoderados apetites, que definia a casa-grande" (Araújo, 1994, p. 59). Há aí um processo que Freyre denomina de ocidentalização da sociedade brasileira. O surgimento da figura do bacharel, por exemplo, é entendido como um elemento moralizador que impõe novos hábitos de civilidade ao seu ambiente social, ligados a um "ideal de comedimento, de cultivo espiritual e de vida de gabinete" (Araújo, 1994, p. 121). Benzaquen de Araújo faz uma interessante análise do papel da hybris nessa nova realidade constituída. Da mesma forma que os engenhos apresentaram "exageros de natureza sexual" (p. 128), os sobrados, agora, apresentarão um excesso de disciplina, de rigor no encaminhamento do novo "processo civilizador", "o excesso agora [...] torna-se de pureza e não de miscigenação" (p. 161). O "gélido e requintado mundo dos sobrados" (p. 181) acabara levando, ao contrário do que aconteceu no engenho colonial, a um afastamento entre as culturas e etnias.

Ao analisar os dois textos de Gilberto Freyre, tomados numa continuidade, Ricardo Benzaquen de Araújo lança mão de diversas idéias e relações bastante pertinentes para a relação que busco construir. Os dois textos apresentam um choque no que diz respeito à oposição entre sexualidade violenta, onipresente, e civilização disciplinarizadora, castradora. Essa tensão é marcada pela hybris, conceito já citado e que merece comentário mais extenso. Benzaquen faz uso desta idéia grega para aplicá-la a Gilberto Freyre. Sua leitura de Os trabalhos e os dias, de Hesíodo, dá destaque a este conceito, que é entendido como excesso, desmedida, na chave proposta por Mary Lafer (1990):

(...) é justamente uma das modalidades dessa hybris, o excesso de natureza sexual, que pode ser apontado como o maior responsável por aquela atmosfera de intimidade e calor que, sem descartar o despotismo, caracterizava as relações entre senhores e escravos em Casa-grande \& senzala. [...] Dessa maneira, em vez da caridade, 
do rigor e da serenidade que orientavam aquele pedagógico modelo cristão, temos o predomínio da irracionalidade e do furor típico da paixão, convertendo a casa-grande e sua patriarcal família em um cenário de rivalidades e desejos. (Araújo, 1994, p. 56).

Um outro aspecto do conceito de hybris diz respeito às conseqüências desses excessos. O desregramento, no mundo grego, vinha associado a tragédias. Para Benzaquen de Araújo (1994, p. 60), a hybris "vem associada a vermes e doenças, isto é, à morte." A sífilis, por exemplo, seria uma conseqüência nefasta de práticas sexuais desregradas praticadas entre senhores e escravas. No entanto, como fica claro na análise freyreana, este desregramento não é visto unicamente como um elemento degradante na formação da sociedade colonial. Pelo contrário, ele teria sido bastante positivo no sentido da conquista do domínio de uma área tropical tão difícil de ser ocupada e explorada. Desta forma, "o relativo elogio que Gilberto faz à loucura em Casa-grande \& senzala garante que a hybris também esteja presente tanto no que rebaixa quanto no que redime a vida social, na violência e no despotismo do mesmo modo que na intimidade e na confraternização" (Araújo, 1994, p. 70). Confraternização e despotismo, mistura de raças e culturas e violência: essa ambivalência gerada pelos excessos, especialmente os da vida sexual, é uma marca da Sociologia freyreana que se aproxima bastante da dramaturgia e do projeto teatral rodriguiano.

Em um outro momento de sua análise, Ricardo Benzaquen de Araújo compara o ambiente da casa-grande e o ambiente marcado por padrões de civilidade do sobrado, chegando às seguintes conclusões:

(...) tanto aquela promíscua experiência da casa - grande quanto a atmosfera crescentemente refinada e espiritual que vai envolvendo os sobrados parecem, igualmente, excessivos, ambos assolados pela mais absoluta falta de medida: no primeiro caso, [...] pelo predomínio do sexo e dos instintos, e, no segundo, em virtude da sua exagerada 
preocupação com a ordem, com a imposição de um sentido rígido, artificial e totalizante à vida cotidiana. (Araújo, 1994, p. 154-155).

Ou seja, se os excessos e a falta de medida guiavam a sexualidade da casa-grande, eles também serviriam como guia para a construção da ordem e do citado sentido totalizante da vida cotidiana. A construção de um "processo civilizador" a partir dos sobrados imperiais seria também violento e traria conseqüências danosas, assim como a sexualidade desenfreada no engenho colonial.

Esta tensão entre excessos de natureza sexual e excessos de padrões de comportamento castradores apresentam, entretanto, alguns escapes. Em Sobrados e mucambos, Freyre percebe no ambiente dos mucambos "a humildade, a singeleza, a integração com a natureza, a naturalidade, a solidariedade, em uma palavra, a fraternidade postulada pela ordem franciscana" (Araújo, 1994, p. 166). O franciscanismo, ideal bastante importante para Freyre, é encontrado em sua obra como uma possibilidade de controlar as tensões e os excessos que marcariam o processo histórico brasileiro.

Outro aspecto importante do processo de "ocidentalização" discutido em Sobrados e mucambos, diz respeito ao fato de que o processo de fortalecimento do Estado e dos interesses públicos (processo acelerado a partir de 1808, tendo em vista o balizamento construído por Freyre) não foi suficientemente forte a ponto de recolocar a questão da predominância do nível privado sobre o público. Pelo contrário, em Freyre, percebe-se uma continuidade entre família e Estado. A partir das análises de Élide Rugai Bastos, fica claro que as figuras que formam o Estado brasileiro, para Freyre, ainda são criaturas do sistema patriarcal e transportam seus interesses para o Estado. Dessa forma, o processo de mudança social analisado em Sobrados e mucambos não altera a estrutura pessoalizada e extremamente marcada pela família da sociedade brasileira. 


\section{Apropriações da Sociologia freyreana em Nelson Rodrigues}

É a partir dessas questões que penso a apropriação que Nelson Rodrigues faz, a partir de seu projeto teatral, da Sociologia freyreana. Pensa-se, aqui, como determinadas idéias surgidas na sociologia circulam, tornam-se modelos, tornam-se maneiras de se ver e se pensar a sociedade e cultura brasileiras e são apropriadas pelo teatro. Trata-se da lógica da produção, circulação e consumo de bens culturais. A partir dessa perspectiva, minha análise busca uma aproximação entre esses dois tipos de textos. Pode-se observar que as tensões encontradas nos livros de Gilberto Freyre, tal como as apresentei, parecem ressurgir nos textos de Nelson, em um outro ambiente social. A maior parte de suas peças passa-se no Rio de Janeiro, tendo, muitas vezes, apartamentos, casas burguesas ou suburbanas como cenário. Nesse ambientes, é possível perceber uma série de personagens atordoados pelo excesso sexual, pela força do desejo sexual, os quais parecem remeter a um ambiente como o da casa-grande freyreana. Edmundo, de Álbum de família, sonha com a possibilidade de viver num mundo em que só existisse sua família, onde todo o tipo de relação poderia existir entre seus membros. Diz ele:

Mãe, às vezes eu sinto como se o mundo estivesse vazio, e ninguém mais existisse, a não ser nós, quer dizer, você, papai, eu e meus irmãos. Como se a nossa família fosse a única e a primeira. (numa espécie de histeria) Então, o amor e o ódio teriam de nascer entre nós. (Rodrigues, 1981b, p. 102).

Nessa peça, uma série de incestos acomete os personagens, que vivem presos a uma casa no interior de uma família claramente patriarcal.

Assim como em Casa-grande \& senzala, na dramaturgia rodriguiana a presença da família é uma constante que busca ditar as normas de conduta, dentro de uma estrutura à qual os personagens 
estão presos, onde explodem uma série de desejos, tensões e rivalidades tão desmedidas como as que aparecem na análise sociológica de Freyre a respeito do passado colonial brasileiro.

Além disso, a família possui a função de criar o principal laço de solidariedade entre os personagens, demonstrando uma clara vitória e hipertrofia do nível privado sobre o nível público. Em diversos momentos de tensão, a solução encontrada pelos personagens é se enclausurar em algum ambiente privado e resolver as questões pessoalmente, "homem a homem". Ou seja, as relações entre os personagens dificilmente são intermediadas por instituições públicas (que exercem pouco papel nas peças e aparecem muito ridicularizadas) ou valores claramente públicos. Há uma clara pessoalização dessas relações, o que também está relacionado aos ambientes sociais construídos por Freyre.

A violência, nos textos de Nelson Rodrigues, aparece recorrentemente e de forma banalizada. Tanto entre os membros das famílias como entre grupos familiares diferentes. Aproximando-se da análise de outro importante cientista social - Luis Costa Pinto -, diversas situações dramáticas freyreanas se constituem a partir de lutas entre famílias, entre vizinhos, em ramos de uma mesma família (primos, tios, cunhados). Essas relações pessoalizadas, marcadas pelos laços familiares, geram uma série de conflitos entre os grupos e dentro dos grupos também: conflitos entre a mulher adúltera e o marido, entre o pai e a filha ingênua que aparece grávida, entre o tio e a sobrinha que se encontra com um deputado em um prostíbulo, etc. Todas essas situações rapidamente resvalam para atitudes fortemente violentas: tapas, socos, cuspes na cara, tiros, pontapés se repetem inúmeras vezes em seus textos.

Por fim, a questão do espírito aventureiro e de defesa da honra, muito marcada em Casa-grande \& senzala, impõe-se nos personagens rodriguianos em diversas situações. Personagens que perdem o emprego porque não admitem ouvir falar mal de seus 
times, que buscam ganhar o máximo de dinheiro da maneira mais rápida, que optam por atuar nas situações mais arriscadas, onde o perigo de serem descobertos, vistos, flagrados é enorme também aparecem repetidamente nesta dramaturgia. São sujeitos que circulam por ambientes altamente sexualizados (seja na família, seja no prostíbulo) em contato com prostitutas, com mulheres com imoderado apetite sexual que encantam o imaginário de homens e mulheres.

Por outro lado, há uma série de personagens e situações em que a interdição e o controle da sexualidade impõem-se numa relação tensa com o impulso sexual, por exemplo: tias que cheiram as cuecas dos sobrinhos, impulsos sexuais reprimidos em direção à mãe, à irmã, ao pai, elogio à feiúra e ao enjôo diante de qualquer atitude sexual. A peça Dorotéia retrata diversas situações paradigmáticas desse tipo de comportamento. Três primas vivem em uma casa cobrindo o rosto e o corpo. Elas vivem em constante vigília para não sonharem. O sonho poderia levar ao instinto sexual, a lugares da alma que poderiam afrontar a forte moralidade da casa e da família. Quando uma outra prima - Dorotéia - retorna à casa, D. Flávia, a prima mais exigente do ponto de vista moral, conta para Dorotéia uma história importante em sua família:

Dorotéí - Eu sabia o que aconteceu com a nossa bisavó... Sabia que ela amou um homem e se casou com outro... No dia do casamento...

D. FláVIA - Noite.

DOROTÉIA - Desculpe - noite... Na noite do casamento, nossa bisavó teve a náusea... (desesperada) do amor, do homem!

D. FLÁviA (num grito) - Do homem!

DorotÉIA - Desde então há uma fatalidade na família: a náusea de uma mulher passa a outra mulher, assim como o som passa de um grito a outro grito... Todas nós - eu também! a recebemos na noite do casamento... (Rodrigues, 1981b, p. 200). 
Essa náusea seria um claro elemento metafórico da repressão e disciplinarização em relação ao desejo e ao ato sexual, delegando um papel muito claro para a mulher de família: ela não poderia realizar plenamente seus desejos sexuais com um homem - mesmo com o marido, o desejo deveria ser acompanhado de uma náusea, um mal-estar. Outra metáfora colocada é a impossibilidade de as mulheres da família verem homens. Para elas, todos os homens seriam invisíveis e, assim, a mulher nem concretizava seu prazer sexual e nem poderia, sequer, ver o homem, o que evidencia um exagero (no caso, até mesmo uma caricatura) na criação de valores burgueses e morais entre os personagens rodriguianos.

Outro exemplo que também demonstra o exagero e a violência em relação ao controle da sexualidade pode ser encontrado num relato do personagem Patrício, de Toda nudez será castigada:

Quando eu tinha dez, onze anos, não me lembro. Onze anos. A nossa casa dava pra um capinzal. Um dia, apareceu uma cabra. (...) De um português, sei lá. Então, todo dia, eu me metia no capinzal. (com o maior tesão) Uma vez, uma das minhas tias olhou pelo muro e me viu (começa a rir com sofrimento): - eu, nu, com a cabra. (...) A cabra foi a minha primeira experiência sexual. (...) Então, a minha tia me agarrou. Outras tias me agarraram. Meu castigo era ficar, uma hora, de joelho, em cima do milho. Me botaram num canto, como se eu, um menino, tivesse lepra. (Rodrigues, 1981d, 180-181).

Esses exemplos podem apontar para a discussão da presença de uma forte tensão nas peças de Nelson Rodrigues: tensão entre o desmedido e violento impulso do sexo e, ao mesmo tempo, violentos e excessivos mecanismos castradores e controladores da vida sexual.

Essa tensão, assim como na obra de Freyre, não gera, necessariamente, um rompimento das relações familiares ou de uma determinada cultural política baseada na força das relações individualizadas. Pelo contrário, as tensões se resolvem dentro do âmbito familiar, a partir de mecanismos violentos, pessoalizados 
e praticamente sem nenhuma intervenção ou intermediação de instituições ou interesses públicos. A tensão entre excessos de sexualidade e de normatização gera lutas entre pais e filhos (como Herculano e Serginho, em Toda nudez será castigada), lutas entre maridos e mulheres, entre lógicas da casa e lógicas da rua, tensões essas que são analisadas em diferentes capítulos de Sobrados e mucambos. E todos esses diferentes conflitos não dão conta de desfazer os laços familiares, mesmo que estes passem a ser dominados pela decadência e pela falta de valores que unifique os indivíduos.

Um outro exemplo desta discussão pode ser visto em Os sete gatinhos. Neste texto, o pai de família - Seu Noronha -, é regido por padrões morais tão fortes que chega a proibir o uso do papel higiênico em casa. Ele se mobiliza para que a família garanta um casamento digno à filha mais nova que estudava em um colégio interno, uma vez que suas outras filhas mais velhas não se casaram. No final do primeiro ato, a família recebe a notícia de que a filha mais nova voltaria para a casa. Uma boa parte do segundo ato é reservada ao retorno da menina para casa, que chega junto com o diretor da escola. Este anuncia para Seu Noronha que a menina havia sido expulsa da escola por ter matado um gato na frente das colegas. A decisão da expulsão havia sido tomada numa assembléia com outros pais, ou seja, representaria um interesse público. Não aceitando esta situação, Seu Noronha decide resolver a situação no nível das relações pessoais: pede para as filhas fecharem a casa inteira e enclausuram o diretor da escola (uma figura pública) num sufocante ambiente privado, onde o diretor é xingado, ameaçado de morte. Seu Noronha quer saber se o fato dele ser contínuo havia influenciado na decisão, falam da vulgaridade de sua mulher, ou seja, a discussão ganha contornos claramente da ordem pessoal e privada. Finalmente, a menina assume o delito e o diretor é libertado, sem maiores conseqüências legais para a família, situação que evidencia, de maneira metafórica, como o âmbito das relações individuais se 
sobrepõe ao da ordem pública e do interesse coletivo na dramaturgia rodriguiana.

Mais adiante, descobre-se que a filha mais nova está grávida de um homem casado, ou seja, não poderia se casar com ele. Dessa maneira, a reprodução da família está comprometida. Através de um mecanismo formal e reconhecido socialmente - o casamento -, não seria possível que aquela família se reproduzisse nos mesmos moldes em que havia sido formada, o que gera uma enorme desestabilização em seus membros, que começam a expor todas as brutalidades existentes entre si. No entanto, é curioso que nenhum dos membros da família consegue se imaginar ou se colocar fora daquelas relações. Os laços familiares se degradam mas continuam firmes, chegando ao ponto do pai propor transformar a casa em um "bordel de filhas" sob o seguinte argumento: "se [sua filha] foi de um, pode ser de todos!" (Rodrigues, 1981c, p. 228-229) Parece que se chega a um ambiente familiar semelhante ao da casa-grande freyreana, marcado pela forte presença sexual e irracional e onde acontecem todas as relações sociais possíveis. A manutenção da honra e da unidade familiar gera esse tipo de desfecho violento (violência que se intensifica, ao final da peça, com o assassinato do pai pelas próprias filhas).

Assim como Freyre, também Nelson Rodrigues encontra uma espécie de válvula de escape para as diversas tensões nas quais seus personagens estariam colocados. Adriana Facina, em seu livro Santos e canalhas: uma análise antropológica da obra de Nelson Rodrigues, já aponta para a possibilidade do amor como a forma de se sair da violenta oposição entre uma sexualidade desenfreada, tal como explicitada em Casa-grande \& senzala, e uma sexualidade marcada pelos excessos de normatização. O amor canaliza os excessos e furores para uma relação intensa e concretizada entre duas pessoas. É o caso de Bonitinha, mas ordinária, onde os personagens Ritinha e Edgard, apesar de uma série de tensões familiares, de busca por enriquecimento fácil e por uma série de questões morais 
conseguem organizar suas relações de forma a viver intensamente o amor que existia entre eles. De forma bastante semelhante temos o casal Joice e Oswaldinho, que parecem conseguir viver um tipo de relação distante da tensão entre expressão e controle sexual desmedidos. Ambos os casos se dão em um ambiente urbano, muito mais marcado pelo anonimato, em que aparece a possibilidade de rompimento com os fortes laços pessoais e familiares que aparecem mais claramente nos ambientes suburbanos rodriguianos.

\section{Conclusão}

A tragicidade dos textos de Nelson Rodrigues - sendo sempre levada ao limite da aceitação, da moral, do pudor -, constituiu-se a partir de um ambiente familiar dominado por constante impulso sexual, por desejos incontrolados, mas em permanente tensão com um ideal de castidade, de frieza, de controle dos impulsos (elementos estes analisados por Freyre nos textos aqui apresentados). Há aí uma apropriação de idéias e interpretações de Gilberto Freyre. Indo além, é possível afirmar que, dentro dessa primeira tensão, uma série de outras questões são apropriadas por Nelson Rodrigues: a expressão de uma determinada cultura política em que os padrões de comportamento dos personagens se pautam pelas relações pessoais em detrimento de acordos coletivos e institucionais, a constante presença da violência como forma de regulação da vida social, o lugar da família como central e também regulador da vida social, a presença de uma série de excessos, seja de violência, de pudor, de paixão, de autoridade, todos necessários à constituição das situações trágicas propostas por Nelson.

Enfim, retorna-se à hipótese central deste artigo: o projeto teatral de Nelson Rodrigues é montado a partir de diversos elementos apropriados da Sociologia de Gilberto Freyre. Daí a sua profunda admiração por Gilberto Freyre. Eram muito recorrentes 
as discussões e rompimentos entre Nelson Rodrigues e inúmeros amigos ou pessoas próximas. Ao longo de sua trajetória, poucos foram aqueles aliados que não romperam em algum momento com o dramaturgo ou sofreram fortes críticas em suas colunas. Gilberto Freyre é uma dessas exceções. Pelo contrário, era sempre citado com a mais profunda admiração por Nelson Rodrigues, chegando à grandiloqüência de afirmações como: "Se me perguntassem quais são os brasileiros mais inteligentes que conheço, eu responderia: - Gilberto Freyre, Gilberto Freyre e Gilberto Freyre" (Rodrigues, 1997, p. 73). Ou ainda: "Gilberto Freyre é o maior de todos os brasileiros. Pode empurrar, com o lado do sapato, como uma barata seca, todos esses garotos que andam por aí" (Rodrigues, 1997, p. 73).

\section{Notas}

1 Esta idéia, fundamental na obra de Freyre, é também influência de autores ingleses, como Alfred Zimmern, Herbert Spencer e Franklin Giddings, estando esta relação bastante bem construída no livro de Pallares-Burke.

\section{Nelson Rodrigues as reader of Gilberto Freyre: the theatrical} 'Rodriguean' project combined with the 'Freyrean'

\section{Sociology}

Abstract: This work proposes a reading of Nelson Rodrigues' dramaturgy having in mind some issues that permeate the theatrical field in the second half of the XX Century, the author's position in face of them and the theatrical project that he explains in his texts. Inside a cultural field marked by intense social and political fights, Nelson Rodrigues produces his plays focussing on theatre's purifying and redeeming functions. In opposition to a whole stream of political engaged theatre, the proposed dramaturgy is infested with intense characters (both in their expression and in their sexual repression) whose function would be to purge the audience. That kind of bet on 
a sense and value for the theatre occurs from some alliances, such as, for example, to Gilberto Freyre's Sociology. Reader and profound admirer of the sociologist, Nelson appropriates, for his theatrical project, various elements of the said sociology, such as excessive violence, physical, sexual and sensual (marks of hybris), as well as the analysis of imported civilization patterns, which also impose themselves by violent repression. The tension between elements of immoderation and of discipline generates a series of characters, situations and struggles, which permeate the works and may also be considered as elements of a strategic alliance.

Keywords: Nelson Rodrigues, Gilberto Freyre, theatre, hybris, civilization.

\section{Referências bibliográficas}

ARAÚJO, Ricardo Benzaquen de. Guerra e Paz, Casa-Grande \& Senzala e a obra de Gilberto Freyre nos anos 30. Rio de Janeiro: Ed. 34, 1994.

ARTAUD, Antonin. O teatro e seu duplo. São Paulo: Martins Fontes, 1999.

BASTOS, Élide Rugai. "Raízes do Brasil - Sobrados e mucambos: um diálogo. Perspectivas: revista de ciências sociais, v. 28 p. 19-36, 2005 .

. As criaturas de Prometeu: Gilberto Freyre e a formação da sociedade brasileira. São Paulo, Global, 2006.

BOURDIEU, Pierre. As regras da arte: gênese e estrutura do campo literário. São Paulo: Cia. das Letras, 1996.

CASTRO, Ruy. O anjo pornográfico: a vida de Nelson Rodrigues. São Paulo: Companhia das Letras, 1992.

ELIAS, Norbert. A sociedade de individuos. Rio de Janeiro: Jorge Zahar, 1984. 
ELIAS, Norbert. O processo civilizador. Rio de Janeiro: Jorge Zahar, 1990. v. 1 e 2 .

FACINA, Adriana. Santos e canalhas: uma análise antropológica da obra de Nelson Rodrigues. Rio de Janeiro: Civilização Brasileira, 2004.

FOUCAULT, Michel. História da sexualidade I: a vontade de saber. Rio de Janeiro: Graal, 1998.

FRANCO, Maria Sylvia de Carvalho. Homens livres na ordem escravocrata. São Paulo: UNESP, 1997.

FREYRE, Gilberto. Como e porque sou e não sou sociólogo. Brasília: UnB, 1968.

. Casa-grande \& senzala. Rio de Janeiro: Record, 1999. (1 ${ }^{\text {a }}$ ed. 1993).

. Novo mundo nos trópicos. Rio de janeiro: Topbooks, 2000a. ( $1^{\mathrm{a}}$ ed. 1971).

. Sobrados e mucambos. Rio de janeiro: Record, 2000b. ( $1^{\text {a }}$ ed. 1936).

GUSMÃO, Henrique Buarque de. "Só toca em mim casando!": reinvenções da moralidade burguesa na dramaturgia de Nelson Rodrigues (1941-1978). Monografia (Bacharelado em História) - Universidade Federal do Rio de Janeiro (UFRJ), 2003.

HOLANDA, Sérgio Buarque de. Raizes do Brasil. Rio de Janeiro: José Olympio, 1989. [1 ${ }^{\text {a }}$ ed. 1936].

LAFER, Mary de Camargo Neves. "Introdução" e "Comentários". In: HESÍODO. Os trabalhos e os dias. São Paulo: Iluminuras, 1990.

LOPES, Ângela Leite. Nelson Rodrigues: trágico, então moderno. Rio de Janeiro: Ed. UFRJ, Tempo Brasileiro, 1993.

MACHADO, Roberto (Org.). Nietzsche e a polêmica sobre o nascimento da tragédia. Rio de Janeiro: Jorge Zahar, 2005. 
MACHADO, Roberto (Org.). O nascimento do trágico: de Schiller a Nietzsche. Rio de Janeiro: Jorge Zahar, 2006.

MATTA, Roberto da. O espaço social brasileiro na obra de Gilberto Freyre. In: CASA-grande \& senzala: 50 anos depois. Rio de Janeiro: Funarte, 1985.

. A originalidade de Gilberto Freyre. BIB, n. 24, 1987.

NIETZSCHE, Friedrich. A origem da tragédia. São Paulo: Moraes, 1984.

PALLARES-BURKE, Maria Lúcia Garcia. Gilberto Freyre: um vitoriano nos trópicos. São Paulo: Ed. Unesp, 2005.

PEREIRA, Victor Hugo Adler. Nelson Rodrigues e a obscena contemporânea. Rio de Janeiro: Ed. UERJ, 1999.

PINTO, Luís de Aguiar. Lutas de famílias no Brasil. São Paulo: Companhia Editora Nacional, 1949.

PRADO JÚNIOR, Caio. Evolução política do Brasil. São Paulo: Brasiliense, 1987.

RODRIGUES, Nelson. Teatro completo 1: peças psicológicas. Org. e introdução de Sábato Magaldi. Rio de Janeiro: Nova Fronteira, 1981a.

. Teatro completo 2: peças míticas. Org. e introdução de Sábato Magaldi. Rio de Janeiro: Nova Fronteira, 1981b.

. Teatro completo 3: tragédias cariocas I. Org. e introdução de Sábato Magaldi. Rio de Janeiro: Nova Fronteira, 1981c.

. Teatro completo 4: tragédias cariocas II. Org. e introdução de Sábato Magaldi. Rio de Janeiro: Nova Fronteira, 1981d.

. A menina sem estrela: memórias. São Paulo: Companhia das Letras, 1993a.

. O óbvio ululante: primeiras confissões. São Paulo: Companhia das Letras, 1993b.

. A cabra vadia: novas confissões (1995a) São Paulo: Companhia das Letras, 1995a. 
RODRIGUES, Nelson. O reacionário: memórias e confissões. São Paulo: Companhia das Letras, 1995 b.

. O remador de Ben-Hur: confissões culturais. São Paulo: Companhia das Letras, 1996.

. Flor de obsessão: as 1.000 melhores frases de Nelson Rodrigues. São Paulo: Companhia das Letras, 1997.

.Teatro desagradável. Folhetim. n. 7, p. 4-13.

. Entrevista com Nelson Rodrigues. Disponível em: http://www. geneton.com.br. Acesso em: 28 jun. 2007.

SALOMÃO, Irã. Nelson feminino e masculino. Rio de Janeiro: 7 Letras, 2000. 